\title{
Pulmonary Disease Linked to Vaping
}

As of August 21, 153 cases of severe respiratory disease associated with vaping had been reported to the CDC mostly in adolescents and teens (1). Cases have been reported in 16 states including California and New Mexico. No specific cause has been identified although the available evidence does not suggest and infectious source. Many of the cases appear similar with tetrahydrocannabinol (THC) containing products often mixed with the vaping solution (2). Patients' respiratory symptoms at presentation included cough, shortness of breath and fatigue that worsened over several days or weeks before hospital admission. Some patients also reported fever, chest pain, weight loss, nausea or diarrhea. Chest radiographs have been reported to show bilateral opacities and CT chest scans have demonstrated diffuse ground-opacities, often with sub-pleural sparing. In some cases, patients experienced respiratory failure requiring mechanical ventilation but subsequently improved with treatment with corticosteroids.

The Arizona Department of Health issued a warning to the public yesterday. If a case is suspected, the Arizona Poison and Drug Information System should be contacted at 800-222-1222.

Richard A. Robbins, MD

Editor, SWJPCC

\section{References}

1. CDC. CDC, FDA, states continue to investigate severe pulmonary disease among people who use e-cigarettes. August 21, 2019. Available at:

https://www.cdc.gov/media/releases/2019/s0821-cdc-fda-states-e-cigarettes.html (accessed 8/22/19).

2. CDC. CDC urges clinicians to report possible cases of unexplained vapingassociated pulmonary illness to their state/local health department. August 14, 2019. Available at: https://emergency.cdc.gov/newsletters/coca/081619.htm (accessed 8/22/19). 